\title{
Neurophysiological Evidence for the Time Course of Activation of Global Shape, Part, and Local Contour Representations during Visual Object Categorization and Memory
}

\author{
Haline E. Schendan ${ }^{1}$ and Marta Kutas ${ }^{2}$
}

\begin{abstract}
Categorization of visual objects entails matching a percept to long-term representations of structural knowledge. This object model selection is central to theories of human visual cognition, but the representational format(s) is largely unknown. To characterize these neural representations, eventrelated brain potentials (ERPs) to fragmented objects during an indirect memory test were compared when only local contour features, but not global shapes of the object and its parts, differed between encoding and retrieval experiences. The ERP effects revealed that the format of object representations varies across time according to the particular neural processing and memory system currently engaged. An occipitotemporal P2(00) showed implicit memory modulation to items that repeatedly engaged similar perceptual grouping processes but not items that merely reinstantiated visual features. After $500 \mathrm{msec}$, memory modulation of a late positive com-
\end{abstract}

plex, indexing secondary categorization and/or explicit recollection processes, was sensitive to local contour changes. In between, a frontocentral N350, indexing the model selection and an implicit perceptual memory system, showed reactivation of object representations whenever the same global shapes were reactivated, despite local feature differences. These and prior N350 findings provide direct neurophysiological evidence that the neural representations supporting object categorization include knowledge beyond local contours and about higher-order perceptual structures, such as the global shapes of the object and its parts, that can differ between object views. The N350 is proposed to index a second state of interactive, recurrent, and feedback processing in occipital and ventral temporal neocortex supporting higherorder cognitive abilities and phenomenological awareness with objects.

\section{INTRODUCTION}

People quickly categorize objects and are even faster and more accurate when seeing an object again, especially when it looks the same, relative to if the image of the object differs somehow, as when seen from another viewpoint. This categorization ability involves matching a percept to representations of visual structural knowledge about objects in long-term memory and selection of the specific known class to which the object belongs (e.g., car, dog, or sofa). The formats of the representations in the human brain supporting this process of object model selection are central to any theory of visual categorization, as well as object memory, but relatively little is known about them. In two experiments, we used event-related brain potentials (ERPs), a technique with exquisite timing sensitivity, to probe these neural representations directly at each moment in processing. In

${ }^{1}$ Tufts University, Medford, MA, ${ }^{2}$ University of California, San Diego (UCSD)

our prior research (Schendan \& Kutas, 2003), ERP findings of viewpoint-dependent memory effects supported the multiple-views-plus-transformation account of visual cognition, which posits that the representational format of an object involves multiple two-dimensional (2-D) views (Bülthoff, Edelman, \& Tarr, 1995). Views differ from each other, however, not just in viewing angle but also in the global 2-D shape of the whole object and of its parts and in more local contours. The corresponding object properties, such as the global spatial configuration of the object or its parts in three dimensions, have been proposed as possible formats for object representations (Cave \& Kosslyn, 1993; Biederman, 1987), but local contours are considered unimportant on the basis of indirect behavioral or hemodynamic evidence in humans or single neuron findings in monkeys (Tanaka, 2003; Kourtzi \& Kanwisher, 2001; Bülthoff et al., 1995). Here, we assessed the role of global shapes versus local contour features in object representation by comparing ERPs to object images under memory conditions in which the local contours 
between initial and subsequent experiences differ but the higher-order structures of global shape of the whole object and its parts did not.

In both experiments, long-term memory representations for objects were probed using an indirect test: Participants categorized objects during an incidental study phase and a later test without being asked explicitly to use their memory for the prior study episode on the test. Under such circumstances, repetition priming is typically observed wherein categorization is faster and more accurate for repeated than for new objects. Such priming measured via an indirect test is thought to depend upon facilitated processing in perceptual representation systems (PRSs) that contribute to implicit memory without conscious awareness (Tulving \& Schacter, 1990). Object priming, in particular, is thought to depend upon object-sensitive areas of the posterior ventral neocortex (James \& Gauthier, 2006; Grill-Spector et al., 1999; Buckner et al., 1998; Schacter et al., 1995). Priming can also reflect conceptual implicit memory involving temporal lobe and ventrolateral prefrontal areas implicated in semantic processing (Simons, Koutstaal, Prince, Wagner, \& Schacter, 2003; Wagner, Maril, \& Schacter, 2000; Gabrieli et al., 1994) or rapid response learning (Dobbins, Schnyer, Verfaelle, \& Schacter, 2004). Implicit memory contrasts with episodic explicit memory that depends upon medial-temporal lobe structures and supports $d i$ rect tests of conscious recognition and recall (e.g., Squire, 1992). Indirect memory tests are considered better suited than direct tests for characterizing perceptual processes and representations (Grill-Spector et al., 1999; Biederman \& Cooper, 1991).

In addition to testing hypotheses about global shapes versus local features, our designs also allowed us to contrast these accounts with various transfer appropriate processing (TAP) accounts, according to which memory is better, the more appropriate the transfer between the component processes engaged upon initial exposure during study and the specific neural processes engaged at test (Leboe, Whittlesea, \& Milliken, 2005; Morris, Bransford, \& Franks, 1977). Typically, processing transfer has been assessed by varying the tasks while using physically similar items during the study and test experiences. When the same stimuli are repeated, however, it cannot be known how much of the memory, if any, may also be due to physical feature overlap between the study and test experiences, as opposed to transfer of the appropriate processes, per se. Our design avoids this confound by using image pairs, wherein both members recruited similar perceptual grouping processes (Koffka, 1935) but did not share any local contours: One picture had lines where its complementary fragment had gaps, and vice versa (Figure 1). In both experiments, participants first categorized fragmented and intact line drawings of objects. During the subsequent memory test, participants categorized fragmented pictures of objects that they had not seen at all before
(Unstudied) or had seen previously in one of several forms: namely, the Same fragmented form or the Complementary fragments, or an intact picture with continuous lines (Experiment 1, Intact) or segmented lines (Experiment 2, Intact-Segmented). Experiment 2 also included a study condition in which the same fragmented picture was drawn with lines half the length of the fragments at test (Half).

Memory-related ERP effects are seen in voltage differences between studied and new items-so-called ERP repetition effects. Unlike a response time (RT) measure, which can reflect any of the many representations and processes potentially contributing to memory, ERPs measure continuously how specific cortical activity at each moment contributes to memory. The hypothesized functional significance of the ERP component modulated can be used to interpret each ERP repetition effect. For the present experiments, the components of interest were: (1) early potentials (300 msec or less) reflecting sensory and perceptual processing, for which the results have been described elsewhere (Schendan \& Kutas, in press); (2) the frontocentral N350 between 300 and $400 \mathrm{msec}$ proposed as a neurophysiological marker of the object model selection system and object PRS (Schendan \& Kutas, 2002, 2003); (3) the posterior N400 between 400 and $500 \mathrm{msec}$ thought to reflect semantic processing and conceptual implicit memory (Rugg et al., 1998); and (4) a late positive complex (LPC) after 500 msec, encompassing a P600 peak, reflecting secondary categorization-related processes (Schendan \& Kutas, 2002) and/or recollection from episodic explicit memory (Duarte, Ranganath, Winward, Hayward, \& Knight, 2004; Paller, Kutas, \& McIsaac, 1995).

Our main aim was to examine the frontocentral N350 to test the global shapes hypothesis that memory depends upon the extent to which the global shapes (of the whole object and/or its intermediate parts), but not the local contours configuring these shapes, overlap between the study and test images of the object. In our experiments, studied objects were always seen in the identical view (and corresponding global shapes) at both study and memory test, but local features could differ (i.e., line orientation, spatial location, or size). The global shapes hypothesis thus predicts equivalent ERP repetition effects in all conditions (Table 1).

By contrast, the local features hypothesis states that memory depends upon the extent to which local contour features overlap between study and test stimuli. This hypothesis also predicts large ERP repetition effects for the same fragment and both intact conditions because the study and test images share identical stimulus features (Table 1). However, unlike the global shapes idea, the local features hypothesis predicts no or smaller repetition effects in the other two test conditions where the local contours differ between study and test, either entirely (Complementary fragments) or partially (Half fragments). 
Figure 1. Methods for Experiments 1 and 2. Both experiments had a study phase (left) followed by an indirect memory test phase (right). In both experiments, participants studied (A) the Same, or (B) the Complementary fragment. In Experiment 1, participants also studied pictures that were (C) Intact, constructed by overlapping the two complementary fragments. (D) In both experiments, an Unstudied condition had objects not shown previously in the study phase. In

Experiment 2, participants studied (E) the same fragment but with line segments of Half the length, and (F) pictures that were Intact-Segmented, created by overlapping the two complementary fragmented versions of the object in different colors (i.e., red for one fragment [outline segments in figure] and green for the other one that was also the test fragment [single lines in figure]). In Experiment 2, therefore, in the study phase, pictures in Same, Complementary, and Half conditions were also drawn in green ink, and, in the test phase, all fragmented pictures were drawn in green ink. Each object was shown for $5000 \mathrm{msec}$ in the study phase and $17 \mathrm{msec}$ in the memory test phase. Participants pressed a key as soon as they categorized the object. Finally, after the object disappeared, participants rated their categorization confidence and named the object. Note that in the test phase these responses were not reported until a cue (?) appeared.

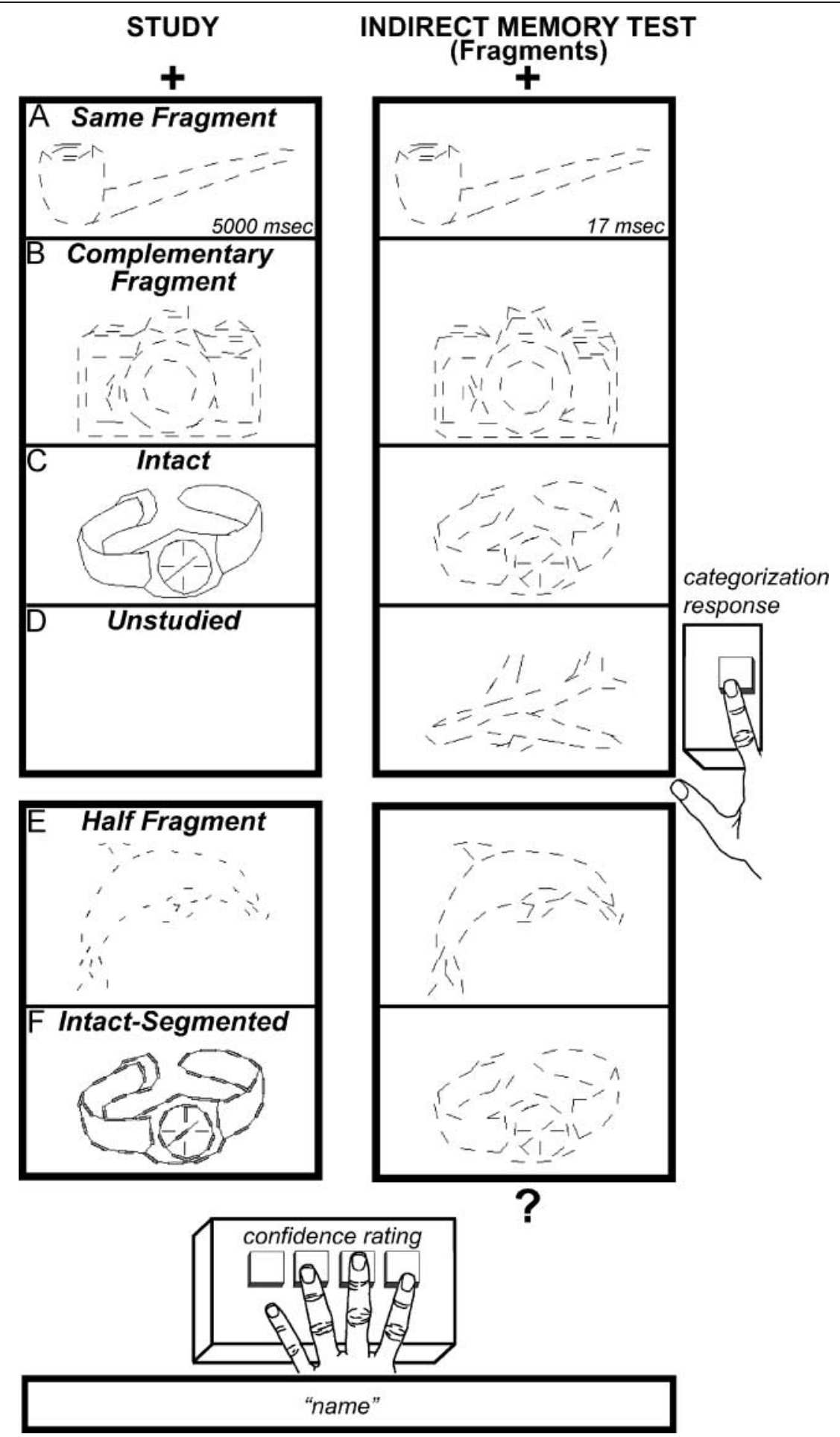

On the other hand, both TAP hypotheses attribute memory effects after studying fragmented pictures (i.e., Same, Complementary, and Half) to the appropriate transfer of specific perceptual processes from the study to the test fragments, irrespective of local feature differences. Unlike both the stimulus-based hypotheses, neither TAP hypothesis predicts any repetition effect in the Intact condition (Table 1) because studying com- plete pictures with uniformly connected lines does not engage the same perceptual processes that the fragmented pictures of the same object recruit at test. The grouping TAP hypothesis would state that this is because memory depends upon the extent to which perceptual grouping processes transfer appropriately between the study and test exposures (Schendan \& Kutas, in press). By contrast, a segmentation TAP hypothesis would 
Table 1. Predicted Pattern of ERP Repetition Effects (Studied vs. Unstudied Condition) across the Study Conditions in Experiments 1 and 2 Based on Each Hypothesis

\begin{tabular}{|c|c|c|c|c|}
\hline \multirow[b]{2}{*}{ Study Condition } & \multicolumn{4}{|c|}{ Hypothesis } \\
\hline & Grouping TAP & Segmentation TAP & Global Shapes & Local Features \\
\hline \multicolumn{5}{|l|}{ Experiment 1} \\
\hline Same fragment & ++ & ++ & ++ & ++ \\
\hline $\begin{array}{l}\text { Complementary } \\
\text { fragment }\end{array}$ & ++ & ++ & ++ & + or 0 \\
\hline Intact & 0 & 0 & ++ & ++ \\
\hline \multicolumn{5}{|l|}{ Experiment 2} \\
\hline Same fragment & ++ & ++ & ++ & ++ \\
\hline $\begin{array}{l}\text { Complementary } \\
\text { fragment }\end{array}$ & ++ & ++ & ++ & + or 0 \\
\hline Half fragment & ++ & ++ & ++ & + or 0 \\
\hline Intact-Segmented & 0 & ++ & ++ & ++ \\
\hline
\end{tabular}

$++=$ repetition effect; $+=$ reduced repetition effect; $0=$ no repetition effect.

say that memory depends upon the extent to which image segmentation processes transfer. On this last account, such complete (Intact) images may produce no memory effect because they differ from fragmented pictures in terms of uniform connectedness, "closed regions of homogeneous properties tend to be perceived initially as single units" (Palmer \& Rock, 1994; but see Peterson, 1994). For all fragmented study pictures, as well as the Intact-Segmented images, each line segment would therefore be one closed region, many of which compose each object. In contrast, for the Intact pictures, the entire uniformly connected contour that outlines each shape would be a single closed region. Segmentation is thus highly salient in all studied images, except Intact. Therefore, each TAP hypothesis makes different predictions for the Intact-Segmented condition: The image segmentation TAP hypothesis predicts repetition effects, whereas the grouping TAP hypothesis does not (Table 1).

As we have reported (Schendan \& Kutas, in press), the pattern of repetition effects on a P2(00) component in these experiments supports the perceptual grouping TAP hypothesis: Relative to new objects, an occipital P2 index of grouping processes in visual cortex (Khoe, Freeman, Woldorff, \& Mangun, 2006) is smaller (i.e., primed) only for studied objects for which similar good continuation and closure processes were repeatedly engaged, regardless of feature differences (Same, Complementary, and Half conditions), and not for objects that merely reinstantiated identical features (Intact or Intact-Segmented). These findings provide support for the critical role of processing, specifically, TAP, for memory, relatively early in visual analysis. Here, we examine later (post $300 \mathrm{msec}$ ) potentials to see whether repeti- tion effects on them can also be best accounted for by TAP, local feature, or global shape accounts. ${ }^{1}$ Our ERP results revealed that the N350 repetition effects were consistent with the global shapes hypothesis, whereas the later LPC effects were consistent with a local feature hypothesis (Table 1; Figure 5).

\section{EXPERIMENT 1}

\section{Methods}

Materials

In-house software generated intact and two complementary fragmented versions (Figure 1) of 272 line drawings of objects, including the Snodgrass and Vanderwart (1980) set. The software required simplifying the drawings by removing extraneous lines and texture, and by adding pixels to close figures. Fragments drawn with the first line segment placed in the upper left corner were "Odd"; "Even" fragments were complementary to this. Fragmented pictures had lines of equal length separated by gaps of the same length $\left(0.5^{\circ}\right)$. Intact pictures were constructed by overlapping both complementary fragments.

\section{Design}

A $2 \times 2$ repeated-measures factorial design (Figure 1A-D) used variables of grouping and feature (see Analyses). Each of four matched (Snodgrass \& Vanderwart, 1980) lists of 68 objects had an Odd and Even variant, corresponding to the Odd/Even type of all memory test fragments (e.g., for List 1-Odd, all test fragments were Odd, and so, at study, when assigned to the Same condition, the fragments would be Odd but, when 
assigned instead to Complementary, then the fragments would be Even). Lists were fully counterbalanced across conditions between subjects. Conditions were shown randomly intermixed.

\section{Procedure}

During both the study and later test phases (Figure 1), objects were shown in white against a black background on a monitor $62 \mathrm{~cm}$ away. Each trial began with central fixation (+) for $700 \mathrm{msec}$ followed 1100 to $1600 \mathrm{msec}$ later by one picture of an object (A-D) for $5000 \mathrm{msec}$ at study and $17 \mathrm{msec}$ in the memory test. Participants pressed a hand-held button (dominant hand) as soon as they categorized the object: categorization response. To minimize movement artifacts, they remained still from fixation, at study, until at least $2 \mathrm{sec}$ after the object appeared or, at test, until a cue appeared (?) 1750 to $2500 \mathrm{msec}$ after the object disappeared. After the picture disappeared at study or the cue appeared at test, they pressed one of four keys (nondominant hand) to report confidence (very sure, sure, unsure, very unsure) that that their prior categorization response had been correct. Finally, participants named the object. Guessing was encouraged, but, if they had no idea, participants withheld the categorization response and said "Don't know."

During the indirect memory test phase, studied and unstudied objects were shown in fragmented form. Three blocks were separated by rest periods; the first block started with five novel filler objects and the other two with one novel filler. Experimental conditions differed only in terms of the images seen during the prior study phase: Objects were studied as (a) the Same or (b) Complementary fragment, or (c) Intact pictures. (d) An Unstudied condition had objects not shown previously in the study phase. Practice sessions with three or six nonexperimental objects preceded study and test phases, respectively. Between study and test, the WAIS-R Information subtest (Wechsler, 1981) estimated verbal IQ and served as a distractor task and delay ( $10 \mathrm{~min})$. After the test phase, the WAIS-R Block Design subtest estimated performance IQ.

\section{Electrophysiology}

Electroencephalographic (EEG) activity was recorded following recommended methods (Luck, 2005; Picton et al., 2000). During study and test phases, ${ }^{2}$ EEG was sampled at $250 \mathrm{~Hz}$ (bandpass $0.01-100 \mathrm{~Hz}$; gain $20,000 \times$ or $50,000 \times$ ) from 28 tin electrodes on a plastic cap (Figure 2 ) secured with straps attached to a body harness. Electrode impedances were always kept below $5 \mathrm{k} \Omega$ and usually below $2 \mathrm{k} \Omega$. Cap, right mastoid, and right zygomatic (below the eye to monitor eye blinks) electrodes were referenced to the left mastoid. Electrodes on the outer canthi of both eyes were referenced to each other to monitor saccades. ERPs were calculated by averaging EEG in each condition, excluding trials with above-threshold muscle activity, eye-blinks, horizontal eye movements, and other movement artifacts; any subject with excessive artifacts was excluded from the study. ERPs were time-locked to image onset with a 150-msec prestimulus baseline and were re-referenced to the mean of both mastoids.

\section{Participants}

Participants were 32 healthy UCSD undergraduates: 1828 years of age $(\mu=20) ; 17$ were women; verbal IQ $\mu=$ 10.4 (one score missing); performance IQ $=12.3$ (three scores missing).

\section{Analyses}

Test phase trials were analyzed for objects that were categorized correctly at both study and test phases because spontaneous categorization yields the most priming (Snodgrass \& Feenan, 1990). Categorization was correct if subjects reported names from Snodgrass and Vanderwart (1980), names given in response to intact versions, their synonyms, or a nonperceptual definition. Mixed analyses of variance (ANOVAs) included between-subjects factors of List and Odd-Even fragment. ERP analyses followed recommended methods (Luck, 2005; Picton et al., 2000). Time periods analyzed were the same as in our prior ERP work on object memory (Schendan \& Kutas, 2003): (a) 300-400 msec assessed the N350; (b) 400-500 msec assessed the posterior N400; (c) 500-700 msec assessed a posterior LPC (P600 peak); (d) 700-850 msec assessed later ERPs shown to exhibit format effects, encompassing the later part of the LPC. Mean ERP amplitudes within a time period were submitted to omnibus ANOVAs with a third within-subjects factor of Electrode. One ANOVA covered four midline sites $(1,26,23,6$; labeled as such in results). Another ANOVA covered 12 lateral electrode pairs (unlabeled in results) to assess hemispheric asymmetry with a fourth within-subject factor of Hemisphere (left, right). Huynh-Feldt adjustments to degrees of freedom corrected for violation of the sphericity assumption. To test the hypotheses, the omnibus analyses had an embedded two-way ANOVA with within-subject factors of Grouping (yes, no) and Feature (yes, no): Same (yes grouping, yes feature), Complementary (yes grouping, no feature), Intact (no grouping, yes feature), Unstudied (no grouping, no feature). To further evaluate the repetition effects and hypotheses, six planned pairwise comparisons used mixed ANOVAs with a within-subjects factor of Study. Specifically, to test for repetition effects, ERPs to unstudied items were compared to fragments studied as: (1) Same, (2) Complementary, or (3) Intact. To test hypotheses, studied conditions were compared: (4) Same versus Complementary, (5) Same versus Intact, and (6) Complementary versus Intact. The Hochberg (1988) step-up Bonferroni procedure set acceptable $p$ values per contrast. 
Figure 2. Grand-averaged ERPs between -150 and $850 \mathrm{msec}$ during the indirect memory test in Experiment 1. The repetition effects are shown at all electrodes. The geodesic electrode montage used to record EEG is shown (bottom); note, T5, T6, $26(\mathrm{Cz})$ and $6(\mathrm{Oz})$ are from the 10-20 system. Before 300 msec,

repetition modulated an occipito-temporal P2(00) component. After $300 \mathrm{msec}$, repetition modulated a frontocentral N350 and a posterior LPC, encompassing the N400 and P600 peaks.

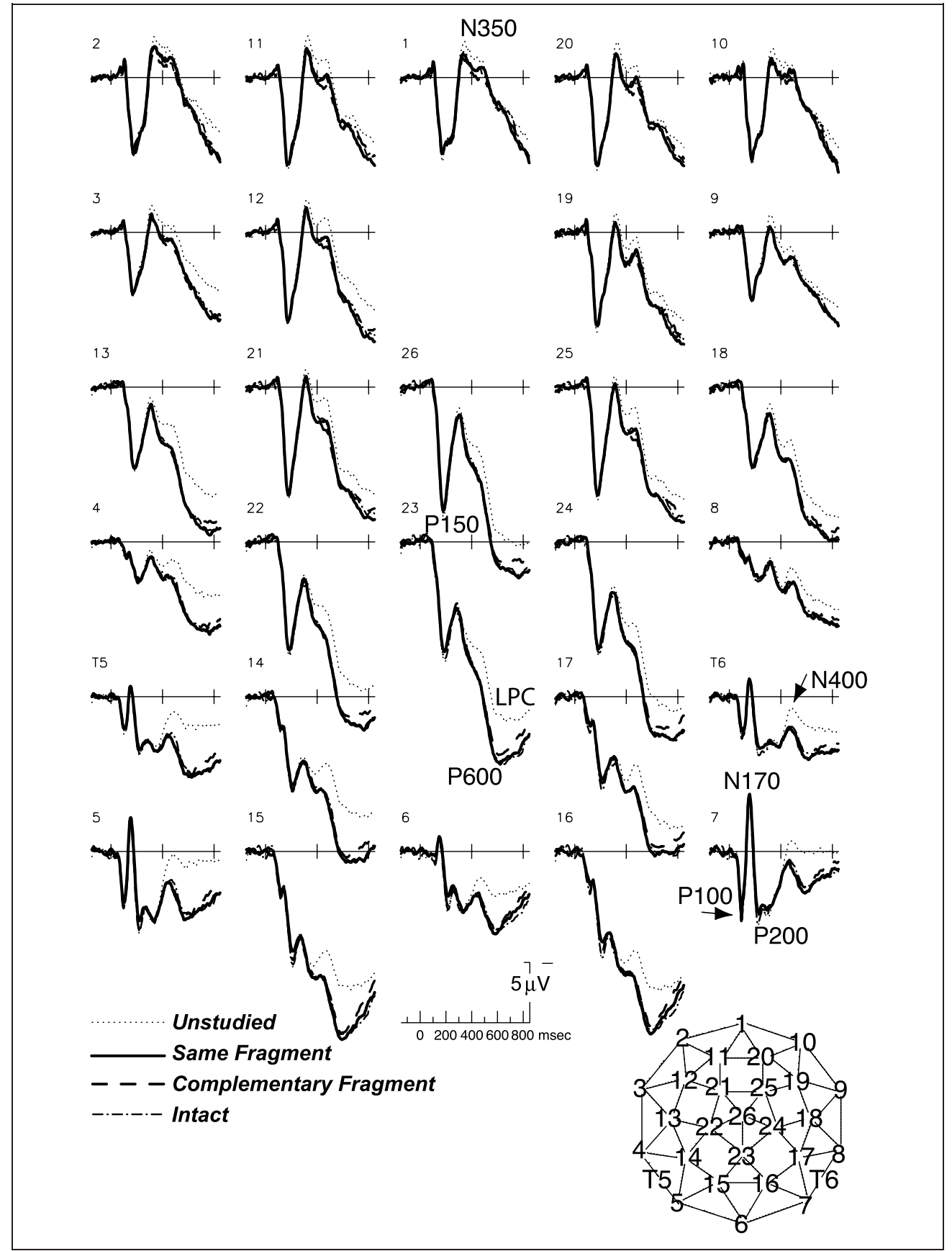

\section{Results}

\section{N350, N400, P600}

Between 300 and 700 msec, ERPs showed general repetition effects: The frontocentral N350 and posterior LPC (encompassing the N400 and P600) were less positive for unstudied than studied objects, which did not differ from each other, consistent with the global shapes hypothesis (Figures 2 and 4A) [for ERPs before $300 \mathrm{msec}$ and performance, see Figure $4 \mathrm{~A}$ and $\mathrm{C}$, and Schendan \& Kutas, in press]. Omnibus ANOVAs showed significant Grouping and Feature main effects and their interaction (Table 2). Effects interacted with Electrode, consistent with the anterior distribution of the N350 and posterior distribution of the $\mathrm{N} 400$ and P600. Interactions with hemisphere showed that $\mathrm{P} 600$ repetition effects were larger over left hemisphere sites. Six planned pairwise comparisons further assessed these results, as revealed in the main effects of Study and/or Study $\times$ Electrode interactions (Hochberg: for N350 and P600, all ps < .0125 ; for $\mathrm{N} 400$, main $p s<.0125$, interaction $p s<.01$ ). Specifically, repetition effects (studied vs. unstudied) were significant for Same during the N350 [main $F(1$, $24)=10.72$, midline $F(1,24)=9.07$; interaction $F(11$, $264)=4.19$ ], N400 [main $F=23.2$, midline $F=24.95$; interaction $F=6.53$, midline $F(3,72)=7.47$, and $\mathrm{P} 600$ 
Table 2. $F$ Values for Significant Effects in Omnibus ANOVAs of ERPs at Each Time Period after 300 msec in Experiment 1

\begin{tabular}{|c|c|c|c|c|c|c|c|c|}
\hline \multirow[b]{2}{*}{ Source } & \multicolumn{2}{|c|}{$300-400 \mathrm{msec}$} & \multicolumn{2}{|c|}{$400-500 \mathrm{msec}$} & \multicolumn{2}{|c|}{$500-700 \mathrm{msec}$} & \multicolumn{2}{|c|}{$700-850 \mathrm{msec}$} \\
\hline & Lateral & Mid & Lateral & Mid & Lateral & Mid & Lateral & Mid \\
\hline Electrode (E) & $31.7 * *$ & $22.2^{* * *}$ & $26.2 * *$ & $25.7 * *$ & $26.2 * *$ & $59.1 * *$ & $44.1 * *$ & $69 * *$ \\
\hline $\mathrm{E} \times \mathrm{H}$ & $5.86 * *$ & & $6.37 * *$ & & $6.88 * *$ & & $5.64 * *$ & \\
\hline Grouping (G) & $5.8^{*}$ & ns & $25.8 * *$ & $18.8^{* *}$ & $23.2 * *$ & $14.9 * *$ & $8.8^{* *}$ & ns \\
\hline $\mathrm{G} \times \mathrm{E}$ & $4.66 * *$ & $22.2^{* *}$ & ns & $n s$ & $11.1 * *$ & $4.86 * *$ & $n s$ & ns \\
\hline $\mathrm{G} \times \mathrm{H}$ & ns & & ns & & $24.68 * *$ & & $18.97 * *$ & \\
\hline $\mathrm{G} \times \mathrm{E} \times \mathrm{H}$ & ns & & ns & & $4.26 * *$ & & $3.38 * *$ & \\
\hline Feature $(\mathrm{F})$ & $6.11 *$ & $5.95^{*}$ & $9.14 * *$ & $13.6^{* *}$ & $32.7 * *$ & $26.6 * *$ & $28.3^{* *}$ & $23.0 * *$ \\
\hline $\mathrm{F} \times \mathrm{E}$ & ns & ns & $4.71 * *$ & $4.27 *$ & $23.6 * *$ & $n s$ & $5.76 * *$ & $5.88 * *$ \\
\hline $\mathrm{F} \times \mathrm{H}$ & ns & & ns & & ns & & $19.92 * *$ & \\
\hline $\mathrm{F} \times \mathrm{E} \times \mathrm{H}$ & ns & & ns & & $4.12 * *$ & & $4.89 * *$ & \\
\hline$G \times F$ & $7.28 *$ & ns & $23.8 * *$ & $13.2^{* *}$ & $32.3^{* *}$ & $24.4 * *$ & $9.4 * *$ & $4.63^{*}$ \\
\hline$G \times F \times E$ & ns & ns & ns & $n s$ & $7.05 * *$ & $n s$ & $n s$ & $n s$ \\
\hline $\mathrm{G} \times \mathrm{F} \times \mathrm{H}$ & ns & & $n s$ & & $32.24 * *$ & & $18.57 * *$ & \\
\hline $\mathrm{G} \times \mathrm{F} \times \mathrm{E} \times \mathrm{H}$ & ns & & ns & & $4.31 * *$ & & $4.1 * *$ & \\
\hline
\end{tabular}

Lateral $=$ lateral electrodes; $\mathrm{Mid}=$ midline electrodes. For $\mathrm{G}, \mathrm{C}$, Hemisphere $(\mathrm{H})$ main effects and interactions $d f(1,24)$; for $\mathrm{E}$ main effects and interactions $d f(11,264)$ and midline $d f(3,72)$. Epsilon values: 300-400 $(\mathrm{E}=.2031 ; \mathrm{mid}=.8414),(\mathrm{G} \times \mathrm{E}=.3908, \mathrm{mid}=.7055),(\mathrm{E} \times \mathrm{H}=.2014) ; 400-$ $500(\mathrm{E}=.2086, \mathrm{mid}=.7800),(\mathrm{C} \times \mathrm{E}=.3191, \mathrm{mid}=.7680),(\mathrm{E} \times \mathrm{H}=.3532) ; 500-700(\mathrm{E}=.2348, \mathrm{mid}=.8287),(\mathrm{G} \times \mathrm{E}=.2725, \mathrm{mid}=.7313),(\mathrm{C} \times$ $\mathrm{E}=.3438, \mathrm{mid}=.6686),(\mathrm{G} \times \mathrm{C} \times \mathrm{E}=.2925),(\mathrm{E} \times \mathrm{H}=.4225),(\mathrm{G} \times \mathrm{E} \times \mathrm{H}=.6577),(\mathrm{C} \times \mathrm{E} \times \mathrm{H}=.4160),(\mathrm{G} \times \mathrm{C} \times \mathrm{E} \times \mathrm{H}=.5814) ; 700-850(\mathrm{E}=$ $.2086, \mathrm{mid}=.7800),(\mathrm{C} \times \mathrm{E}=.3191, \mathrm{mid}=.768),(\mathrm{E} \times \mathrm{H}=.3532),(\mathrm{G} \times \mathrm{E} \times \mathrm{H}=.6674),(\mathrm{C} \times \mathrm{E} \times \mathrm{H}=.3785),(\mathrm{G} \times \mathrm{C} \times \mathrm{E} \times \mathrm{H}=.5356)$.

$* p<.05$.

$* * p<.01$.

[main $F=43.77$, midline $F=36.33$; interaction $F=$ 28.55, midline $F=20.75]$; for Complementary during the N350 [main $F=16.9$, midline $F(1,24)=11.99$; interaction $F=5.31$ ], N400 [main $F=56.63$, midline $F=$ 52.53], and $\mathrm{P} 600$ [main $F=45.33$, midline $F=33.91$; interaction $F=15.97$, midline $F=14.47]$; and for Intact during the N350 [main $F=12.32$, midline $F=7.73$; interaction $F=4.01$ ], N400 [main $F=26.87$, midline $F=25.48$; interaction $F=4.93$, midline $F=6.86]$, and P600 [main $F=52.2$, midline $F=41.06$; interaction $F=31.25$, midline $F=32.76]$. In contrast, comparisons among studied conditions were not significant $\left(F_{\mathrm{S}}<2\right.$, ps $>.11$ ), as the global shapes hypothesis predicts.

\section{Later ERPS}

After $700 \mathrm{msec}$, the posterior LPC was still larger to studied than to new objects, especially over the left hemisphere, but now differed among studied conditions, as a local features idea predicts (Figures 2 and 4A, B). Omnibus ANOVAs showed significant main effects of Grouping and Feature that interacted with each other and/or Electrode and/or Hemisphere (Table 2). Six planned pairwise comparisons showed main effects of Study and/or Study $x$ Electrode interactions (Hochberg: main $p<.0167$, midline $p<.0125$; interactions $p s<.01)$ : Repetition effects (studied vs. unstudied) were significant for Same [main $F=23.65$, midline $F=15.3$ ], Complementary [main $F=$ 14.28 , midline $F=7.66$ ], and Intact [main $F=24.05$, midline $F=15.96$, interaction $F=5.81$, midline $F=5.35$ ]; comparisons among studied conditions were significant between Complementary and Intact conditions [interaction $F=6.32$, midline $F=7.3, p s<.0004]$, between Same and Complementary [main $F=7.42, p=.0118$ ], and marginally between Same and Intact [interaction $F=$ $2.72, p=.0333$, midline $F=2.91, p=.0406]$.

\section{Onset Latency}

Onset time of N350 repetition effects was estimated using a series of point-by-point, three-way mixed ANOVAs on ERPs at each electrode. Tests started during the P200 from 200 to $300 \mathrm{msec}$ (Schendan \& Kutas, in press) because N350 repetition effects start within $200 \mathrm{msec}$ (Schendan \& Kutas, 2003). The time when consecutive points first showed a significant main effect of study (Same or Complementary vs. Unstudied) was taken as the onset (Picton et al., 2000). The P200 onset was found to be within $200 \mathrm{msec}$ of stimulus onset at occipitotemporal sites 5, 7, 15, 16, T5, and T6 for Same versus 
Unstudied and sites 7 and 16 for Complementary versus Unstudied, remaining significant until 252 msec. In contrast, the N350 started after the P200 onset, specifically, by $288 \mathrm{msec}$ for Same versus Unstudied and by $248 \mathrm{msec}$ for Complementary versus Unstudied at frontal site 11, as well as before $300 \mathrm{msec}$ at sites 20 and 12 .

\section{EXPERIMENT 2}

\section{Methods}

Methods were the same as Experiment 1, except for the following.

\section{Design}

Figure 1(A-B, D, E-F) shows the design. Five experimental conditions were compared within-individuals: studied as (i) Same, (ii) Complementary, (iii) Half, (iv) Intact-Segmented, or (v) Unstudied.

\section{Materials}

To the Experiment 1 set, 68 line drawings of objects were added. To create five lists of 68 objects, the four Experiment 1 lists were used, except that 13 objects from each were randomly chosen to be in a new fifth list. The 68 extra objects were randomly divided into four sets of 13, which were randomly assigned to the four Experiment 1 lists, and one set of 16, which was assigned to the fifth list. To match the objects on the same criteria as Experiment 1, reorganization of objects to lists was required, but numbers of retained and switched objects were the same across lists. Lists were fully counterbalanced across conditions between subjects.

To create Half-segment pictures (Figure 1E), both complementary fragments of each object were modified using Deneba artWORKS. The size of each line segment was reduced by 50\%, maintaining line thickness, location, and orientation. Location corresponded to one end of each original line segment; the same end for each segment in the figure, ensuring that all gaps were the same distance. Intact-Segmented pictures were constructed by overlapping one fragment in green ink, and its complement in red ink, creating pictures with alternating, equiluminant green and red line segments (Figure 1F). All fragmented pictures were green. At test, fragments were the corresponding green, Even or Odd complementary figure composing its Intact-Segmented picture (e.g., if the Even Intact-Segmented version was studied, the Even fragment was tested, and this Even fragment was colored green at both study and test).

\section{Procedure}

The monitor was $93 \mathrm{~cm}$ from the subjects. In the study phase, people received additional instructions describ- ing the Intact-Segmented and Half pictures. Practice beforehand used seven nonexperimental objects. The block design test was not given.

\section{Participants}

Of 40 participants, 24 were women, 18-28 years of age $(\mu=20.5)$, verbal IQ $\mu=10.4$.

\section{Analyses}

Acceptable verbal labels for the extra 68 objects were those given to Intact-Segmented pictures. The List factor had five levels. Omnibus ANOVAs had a Study factor (Same, Complementary, Half, Intact-Segmented, Unstudied). To evaluate the basic repetition effect, planned ANOVAs contrasted Same versus Unstudied. To test the hypotheses using the four studied conditions, mixed ANOVAs incorporated a $2 \times 2$ factorial design with factors of Feature (identical or different) and Fragment (same or complement), respectively: Same transfers both (identical, same), Intact-Segmented transfers identical local contour features but also complementary ones (identical, complement), Half transfers the same fragment but only half the features (different, same), Complementary transfers no local features but rather has complementary features (different, complement).

The global shapes and segmentation TAP hypotheses predicted comparably significant repetition effects in all conditions of this experiment (Table 1) and so no main effects of Fragment or Feature or their interaction were expected. The local feature hypothesis predicted a main effect of Feature. The grouping TAP process hypothesis predicted a main effect of Fragment and a Fragment $\times$ Feature interaction, indicating TAP for Same, Complementary, and Half, but not for Intact-Segmented conditions. Four planned simple effects tests further evaluated the interaction: The critical two contrasts were (i) Same versus IntactSegmented and (ii) Half versus Complementary, but for completeness, (iii) Same versus Half and (iv) IntactSegmented versus Complementary were also tested. The grouping TAP hypothesis predicted effects for (i) and (iv).

\section{Results}

N350

As in Experiment 1, between 300 and 400 msec, the N350 to all studied items was less negative than to unstudied items (Figure 3) [for ERPs before $300 \mathrm{msec}$ and performance, see Figure 4C and Schendan \& Kutas, in press]. Omnibus ANOVAs revealed significant effects of Study (Table 3). The pairwise contrast of Same versus Unstudied showed that the N350 repetition effect was significant. A Study effect $[p$ s $<.0005, F(1,30)=15.94$, midline $F(1,30)=20.17]$ interacted with Electrode $[p \mathrm{~s}<.01$, $F(11,330)=7.04, \varepsilon=.2781$, midline $F(3,90)=4.14, \varepsilon=$ 
.8926]; main Electrode effects were reliable [ $p$ s $<.0001$, $F=57.62, \varepsilon=.2236$, midline $F=39.60, \varepsilon=.9173]$.

ANOVAs limited to the four studied conditions demonstrated that N350 repetition effects did not differ among them. There were no significant main effects or interactions with Electrode or with hemisphere for Feature, $F_{\mathrm{S}}<1, p s>.6$, or fragment type, $F_{\mathrm{S}}<2.4$, $p s>13$, or interactions of Feature with Fragment, $F_{\mathrm{S}}<$ 1.9, $p s>$.1. Planned simple effects tests confirmed comparable N350 repetition effects among studied con- ditions (main $F \mathrm{~s}<1.1$, ps $>.3$, interaction $F_{\mathrm{S}}<2.7$, ps $>.1)$.

\section{N400, P600, Later ERPS}

After 400 msec, ERP effects were consistent with the local feature hypothesis. An LPC, encompassing N400, P600, and later ERPs (i.e., 700-850 msec), showed differences between studied conditions, which started earlier in this experiment between 400 and 500 msec (Figures 3
Figure 3. Grand-averaged ERPs between -150 and 850 msec during the indirect memory test in Experiment 2. The repetition effects are shown at all electrodes. The geodesic electrode montage used to record EEG is shown (bottom); note, T5, T6, $26(\mathrm{Cz})$ and $6(\mathrm{Oz})$ were from the 10-20 system. Before $300 \mathrm{msec}$, the early repetition effect affecting a posterior P2(00) was replicated and extended. As in Experiment 1, after 300 msec, repetition modulated a frontocentral N350 and a posterior LPC, encompassing the $\mathrm{N} 400$ and P600 peaks, that continued until around $850 \mathrm{msec}$.

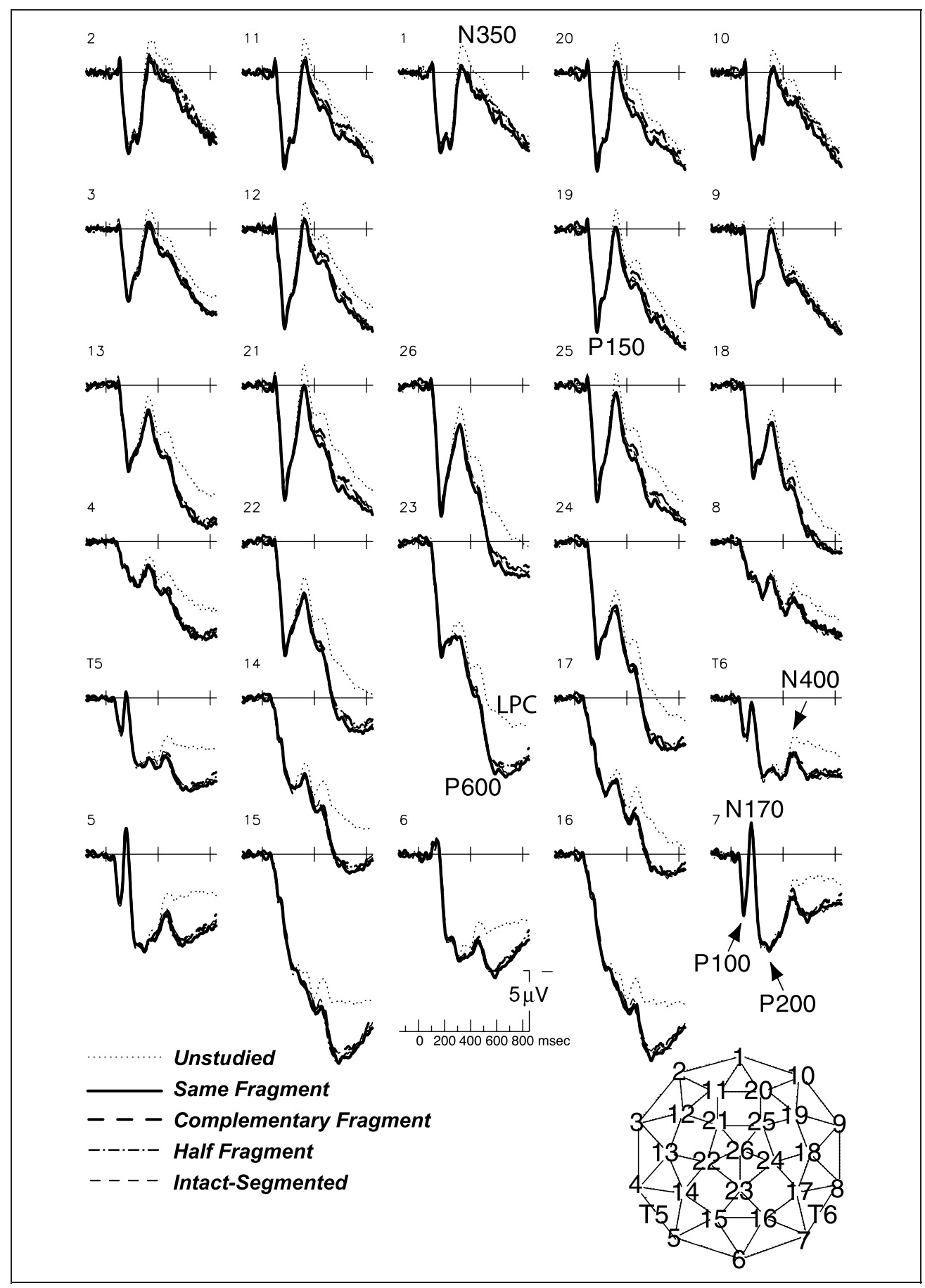


Figure 4. Current source density (CSD) maps, LPC repetition effects, and performance. (A) CSD maps show the distinct distribution across the top of the head of current sources (red) and sinks (blue) for the P200 (226-238 msec), N350 (354-366 msec), and the LPC (700-719 msec; after the $\mathrm{P} 600$ peak); note, because the scalp distributions were similar across conditions and for the two experiments, only the Unstudied condition in Experiment 1 is shown. (B) Grand-averaged ERPs between -150 and $850 \mathrm{msec}$ at midline parietal site 23 (electrode circled in CSD map for LPC) during the indirect memory test in Experiments 1 (left) and 2 (right). LPC repetition effects, starting around the P600 peak, are reduced for Complementary fragments in both Experiments 1 and 2, and, in Experiment 2, for Half fragments, relative to those in Same and Intact(-Segmented) conditions. The solid vertical lines at 700 msec mark the approximate time of the earliest RTs to studied objects in the experiments. (C) Bar graphs show categorization time during the indirect test for Same (black), Complementary (red), Half (blue), Intact(-Segmented) (green), and Unstudied (dotted) conditions in Experiments 1 (left) and 2 (right); note, as reported in Schendan and Kutas (in press), significant RT priming (unstudied studied) was found (FS $>44$, ps < .0001); RTs in the Same condition were significantly (* in figure) faster than in the Complementary condition of Experiment $1[F(1,24)=5$, $p<.04]$ and Experiment 2 $[F(1,30)=10, p<.005]$, and than the Intact condition of Experiment $1(F=13$, $p<.005)$.

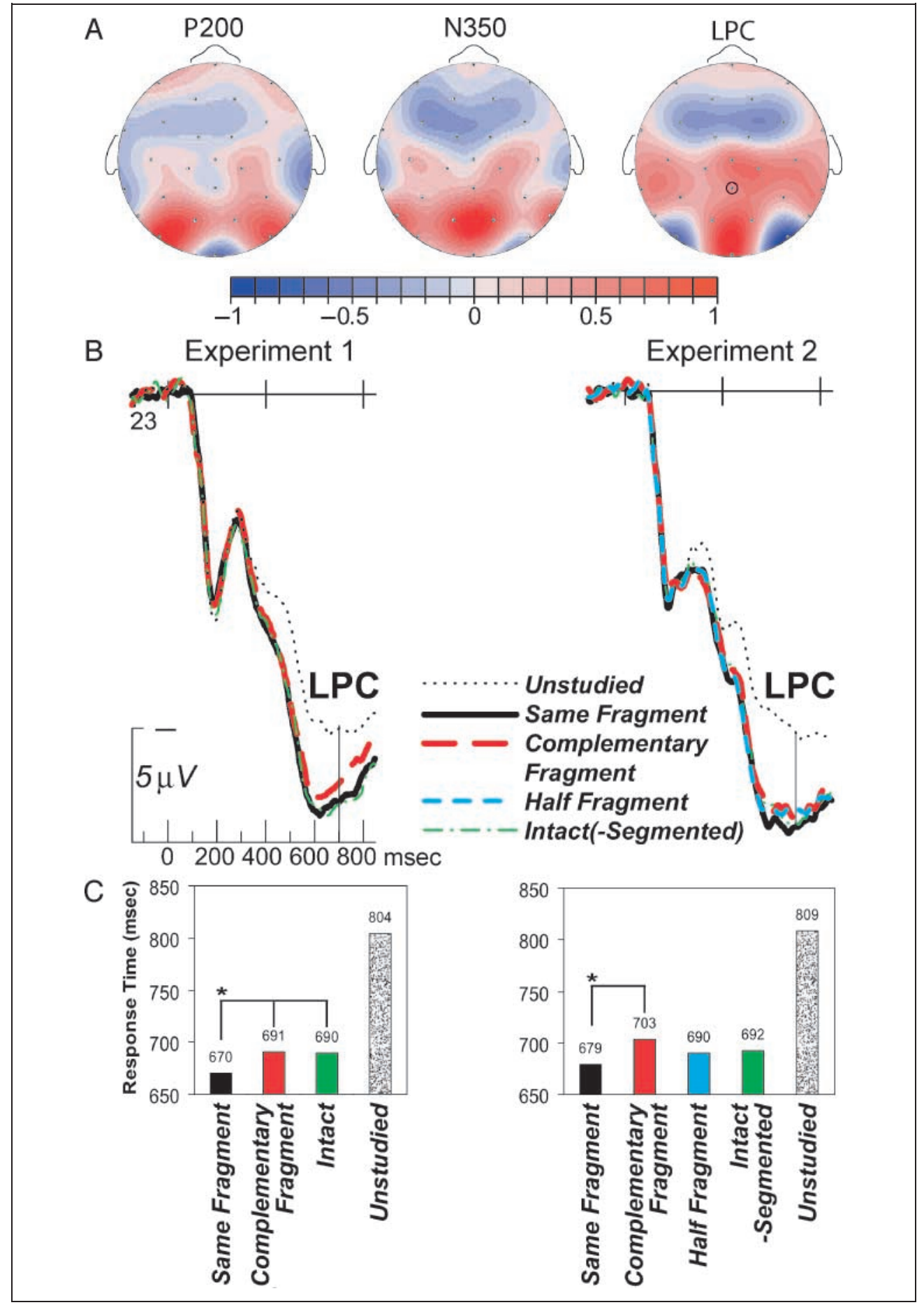

and 4B). Omnibus ANOVAs showed significant Study effects that varied with Electrode and Hemisphere (Table 3). N400, P600, and later ERP repetition effects were significant; pairwise contrasts of Same versus Unstudied showed main effects of Study $(p s<.0001)$ during the $\mathrm{N} 400(F=37.36$, midline $F=48.17), \mathrm{P} 600$
$(F=79.44$, midline $F=96.31)$, and later ERPs $(F=41.95$, midline $F=38.86)$; and Study $\times$ Electrode interactions $(p s<.01)$ for the $\mathrm{N} 400(F=5.21$, midline $F=5.71)$, $\mathrm{P} 600(F=16.01, \varepsilon=.2159$, midline $F=17.44, \varepsilon=$ $.8404)$, and later ERPs $(F=11.13, \varepsilon=.2945$, midline $F=12.54, \varepsilon=.8505)$. 
Table 3. $F$ Values for Significant Effects in Omnibus ANOVAs of ERPs at Each Time Period after 300 msec in Experiment 2

\begin{tabular}{|c|c|c|c|c|c|c|c|c|}
\hline \multirow[b]{2}{*}{ Source } & \multicolumn{2}{|c|}{$300-400 \mathrm{msec}$} & \multicolumn{2}{|c|}{$400-500 \mathrm{msec}$} & \multicolumn{2}{|c|}{$500-700 \mathrm{msec}$} & \multicolumn{2}{|c|}{$700-850 \mathrm{msec}$} \\
\hline & Lateral & Mid & Lateral & Mid & Lateral & Mid & Lateral & Mid \\
\hline Electrode (E) & $58.43 * *$ & $38.72 * *$ & $45.32 * *$ & $37.27 * *$ & $66.24 * *$ & $66.37 * *$ & $68.48 * *$ & $79.47 * *$ \\
\hline $\mathrm{H}$ & $12.26 * *$ & & $12.07 * *$ & & $n s$ & & $n s$ & \\
\hline $\mathrm{E} \times \mathrm{H}$ & $3.77^{*}$ & & $9.63 * *$ & & $14.97 * *$ & & $15.03 * *$ & \\
\hline Study (S) & $7.84^{* *}$ & $9.24 * *$ & $14.22 * *$ & $17.13 * *$ & $34.33 * *$ & $39.59 * *$ & $19.56 * *$ & $17.26^{* * *}$ \\
\hline $\mathrm{S} \times \mathrm{E}$ & $2.16^{*}$ & ns & $2.65^{* *} *$ & $2.67 * *$ & $11.52 * *$ & $11.90 * *$ & $5.68 * *$ & $6.53 * *$ \\
\hline $\mathrm{S} \times \mathrm{H}$ & ns & & ns & & ns & & $5.35 * *$ & \\
\hline $\mathrm{S} \times \mathrm{E} \times \mathrm{H}$ & $n s$ & & $1.97 * *$ & & $2.48 * *$ & & $2.51 * *$ & \\
\hline
\end{tabular}

Lateral = lateral electrodes; $\mathrm{Mid}=$ midline electrodes. $d f$ : For S, $(4,120)$ and mid $(4,120)$; for $\mathrm{E},(11,330)$ and mid $(3,90)$; for S $\times \mathrm{E}(44,1320)$ and mid $(12,360)$; for $\mathrm{H},(1,30)$; for $\mathrm{S} \times \mathrm{H},(4,120)$; for $\mathrm{E} \times \mathrm{H},(11,330)$; for $\mathrm{F} \times \mathrm{C} \times \mathrm{H},(1,30)$. Epsilon values: 300-400 $(\mathrm{E}=.2259$; mid $=.9122)$, $(\mathrm{S} \times$ $\mathrm{E}=.2658),(\mathrm{E} \times \mathrm{H}=.2945) ; 400-500(\mathrm{E}=.2480 ; \mathrm{mid}=.8952),(\mathrm{S} \times \mathrm{E}=.2350, \mathrm{mid}=.8604),(\mathrm{E} \times \mathrm{H}=.3271),(\mathrm{S} \times \mathrm{E} \times \mathrm{H}=.4421) ; 500-700(\mathrm{E}=$ $.2815 ; \mathrm{mid}=.8900),(\mathrm{S} \times \mathrm{E}=.2161, \mathrm{mid}=.7500),(\mathrm{E} \times \mathrm{H}=.3807),(\mathrm{S} \times \mathrm{E} \times \mathrm{H}=.5068) ; 700-850(\mathrm{E}=.3163 ; \mathrm{mid}=.8894),(\mathrm{S} \times \mathrm{E}=.2871, \mathrm{mid}=$ $.7594),(\mathrm{E} \times \mathrm{H}=.3831),(\mathrm{S} \times \mathrm{E} \times \mathrm{H}=.5121)$.

$* p<.05$.

$* * p<.01$.

ANOVAs limited to the four studied conditions showed that ERPs between 400 and $850 \mathrm{msec}$ were more positive for same (i.e., Same) than different (i.e., Complementary, Half) fragments. Even so, results suggested some variation in the pattern over time. In particular, fragment type seemed more important from 400 to $500 \mathrm{msec}$, with ERPs to fragments primed by images involving the same fragment (Same, Half) being more positive than those involving the complementary fragment (Intact-Segmented, Complementary). Main effects of Fragment were significant during the N400 $(F=5.89$, $p=.0215)$, but not the P600 or later ERPs $(F \mathrm{~s}<2$, ps $>$ $.2)$; a Fragment $\times$ Electrode $\times$ Hemisphere interaction was marginal for the P600 $(F=1.94, p=.0640, \varepsilon=$ .6620). In contrast, after $500 \mathrm{msec}$, feature seemed more important, with ERPs to fragments primed by images with identical local features (Same, Intact-Segmented) being more positive than those with changed features (Half, Complementary). Main effects of Feature were not reliable during the N400 ( $F s<1, p s>.4)$ but were significant or marginal during the $\mathrm{P} 600(F=4.88, p=.0350$, midline $F=6.94, p=.0132)$ and later ERPs $(F=3.56$, $p=.0688$, midline $F=5.23, p=.0294)$. A Feature $\times$ Electrode interaction was significant for the P600 ( $F=$ $3.21, p=.0462, \varepsilon=.2247)$ and marginal for the $\mathrm{N} 400$ $(F=2.26, p=.0870, \varepsilon=.2689)$. No Feature $\times$ Fragment interaction was reliable $\left(F_{\mathrm{s}}<1, p \mathrm{~s}>.55\right)$. Four planned simple effects tests revealed no reliable differences, except for the contrast between Same and Intact-Segmented, for which an interaction of Study $\times$ Hemisphere was significant during the later ERPs $(F=5.41, p=.0270)$.

Post hoc contrasts further assessed the pattern of effects $(\alpha=.0083)$. For Same versus Complementary, main effects of Study were significant during the P600 $(F=8.93, p=.0056$, midline $F=6.72, p=.0146)$, and marginal for the N400 $(F=5.79, p=.0225)$ and later ERPs $(F=4.72, p=.0379)$. For Half versus IntactSegmented, interactions of Study $\times$ Electrode were marginal during the $\mathrm{N} 400$ (midline $F=2.97, p=.0365$, $\varepsilon=.9096)$ and $\mathrm{P} 600(F=2.92, p=.0392, \varepsilon=.2303$; midline $F=3.80, p=.0270, \varepsilon=.8193)$, and Study $\times$ Electrode $\times$ Hemisphere were marginal during the N400 $(F=2.78, p=.0196, \varepsilon=.4858)$. Results thus indicated greater positivity for Same and Intact-Segmented than for Complementary and Half conditions (Figure 4B).

\section{DISCUSSION}

We used ERPs to delineate the time course of activation of the representational formats supporting visual object categorization during an implicit memory paradigm. We compared the patterns of ERP (and RT) repetition effects to object images for which the local contours between initial study and subsequent test experiences differed, whereas the higher-order structures of global shape stayed the same in order to assess the role of global shapes versus local contour features in object representation, as well as two TAP accounts. Besides priming effects on RT, we observed multiple, different patterns of ERP repetition effects across time, implicating several diverse representational formats in object categorization and memory (Figure 5). Across two experiments, these included repetition effects on an early occipito-temporal P2(00) indexing sensory-perceptual processing, a somewhat later frontocentral N350 reflecting object model selection and implicit memory system engagement, and a later, post-500 msec posterior LPC reflecting secondary categorization processes and/or incidental recollection (Schendan \& Kutas, 2003). The P200 effects index contributions to memory via transfer 
of perceptual grouping processes, regardless of local features (grouping TAP hypothesis); this finding is detailed in Schendan and Kutas (in press) and so will not be discussed further here. The N350 effects index contributions to implicit memory via overlap of global shapes between study and test, re-engaging a neural system (a PRS) that represents the global shapes of objects and their parts, regardless of size, orientation, and spatial location of local contours (global shapes

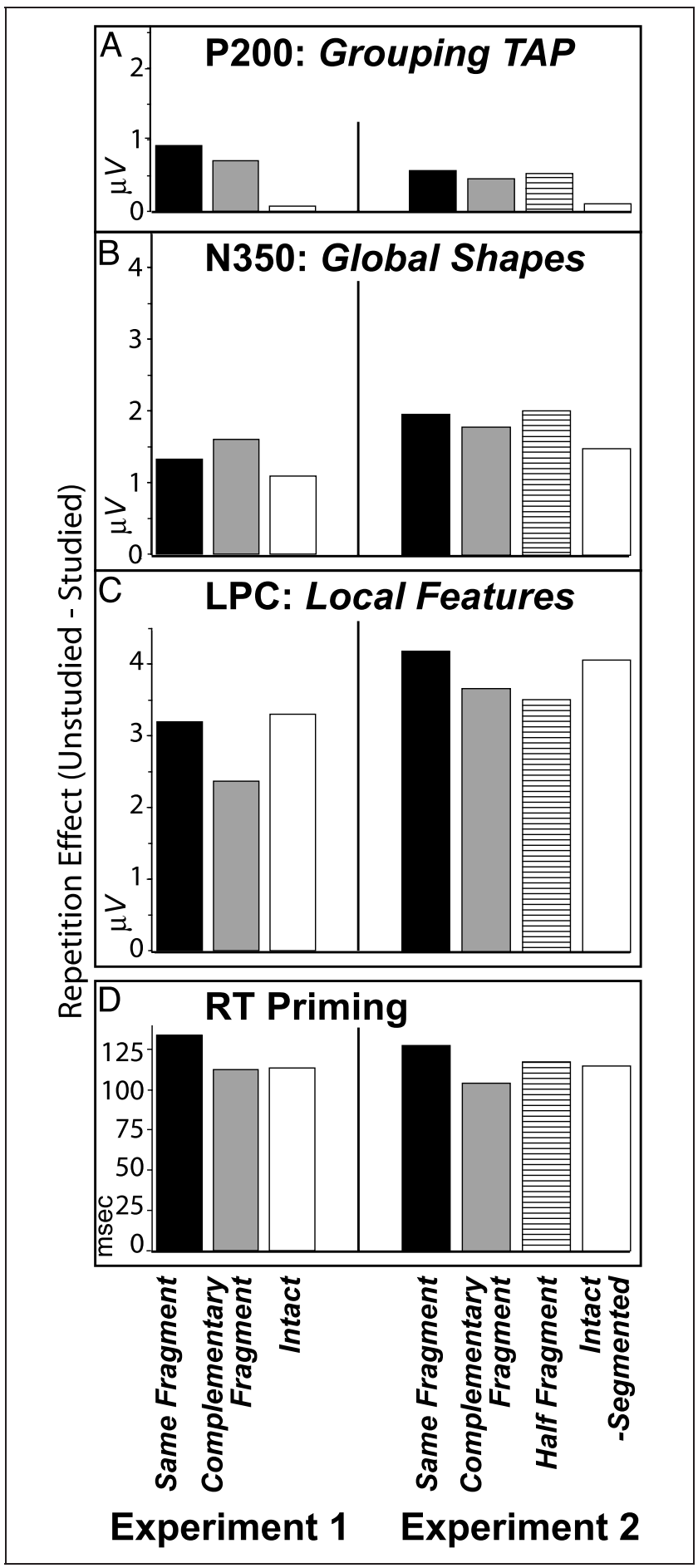

hypothesis). Finally, the LPC effects, which most closely parallel the RT priming, index contributions to memory via overlap of local features between study and test, reengaging a neural system that represents knowledge about the length, orientation, or spatial location of the local contours that make up an object figure (local features hypothesis). Altogether, the time course of ERP repetition effects provides evidence for a multiple memory systems framework in which TAP and an understanding of the processing and representational capabilities of each neural system predicts memory performance (Schendan \& Kutas, 2003; Schendan, Searl, Melrose, \& Stern, 2003).

\section{Frontocentral N350, Object Model Selection, and Memory}

N350 research has shown that the neural system which it reflects supports model selection, generic memory, and perceptual and conceptual implicit memory for objects, and perhaps also familiarity, and contains representations of each 2-D view. The N350 marks the first ERP divergence with categorization success, being smaller for correctly categorized than unidentified objects, and is sensitive to the recoverability of perceptual structure (e.g., Schendan \& Kutas, 2002; McPherson \& Holcomb, 1999). The visual knowledge enabling this categorization ability is a kind of generic memory, that is, explicit memory which is not episodic, such as for recognition and recall tasks, but rather for semantic or nonsemantic (i.e., perceptual) information or facts, regardless of a temporal event context (Hintzman, 1978). The N350 is

Figure 5. Summary of P200, N350, LPC, and RT repetition findings. Bar graphs plotting the size of the repetition effect on the ERPs and RTs for each studied object condition during the indirect test in Experiments 1 (left) and 2 (right). Each repetition effect was computed by subtracting the data in each Study condition from that in the Unstudied condition. These results can be evaluated with respect to the predicted outcomes for different hypotheses in Table 1 : (A) Only images studied in fragmented form show a P2(00) repetition effect (computed between 224 and $240 \mathrm{msec}$ at right occipito-temporal electrode 7). This pattern of repetition effects on the $\mathrm{P} 2$, which indexes implicit perceptual memory, is consistent with the grouping TAP hypothesis (Schendan \& Kutas, in press). (B) The N350 repetition effect (computed for the 350-msec peak at midline frontal electrode 1) is similar in all conditions. This pattern of N350 effects, indexing implicit perceptual memory and PRSs, is consistent with the global shapes hypothesis. (C) The LPC repetition effect (computed at $700 \mathrm{msec}$ at the midline parietal electrode 23) was smaller in the Complementary and Half fragment conditions, the only cases where local contours changed (in orientation and location, or size) from study to test. This pattern of LPC effects, indexing secondary categorization or recollection, is consistent with the local features hypothesis. (D) Priming of categorization RTs is a cumulative function of the P200, N350, and LPC repetition effects; note that RT priming for the Same fragments condition was larger than for the Complementary fragments condition in both experiments, and than the Intact condition in Experiment 1 (Schendan \& Kutas, in press). 
also sensitive to prior visual experience with objects. It is modulated by repetition within an experimental context, being smaller for repeated than for new objects during indirect memory tests (Schendan \& Kutas, 2003), as replicated herein and direct memory tests, and with implicit category learning with an "FN400" being smaller for exemplars that are in than out of the learned class (Curran, Tanaka, \& Weiskopf, 2002). The N350 is also modulated with perceptual expertise (i.e., task training occurring over numerous experiences), a factor that can interact with repetition (Schendan \& Kutas, 2003). Specifically, the N350 shows view typicality effects, being smaller for canonical views, which people experience often, than for unusual ones, which are rarely seen, and N350 repetition effects are smaller for memory test views that are canonical than unusual. Crucially, N350 repetition effects are also view-dependent, being reduced when the viewpoint differs between initial and subsequent exposures. This visual-specificity demonstrates that N350 repetition effects can index perceptual implicit memory (PRSs), but note that the N350 may index conceptual implicit memory (Voss \& Paller, 2006; Holcomb \& McPherson, 1994) or familiarity based on episodic explicit memory with awareness (Curran et al., 2002; Duarte et al., 2004). These N350 findings, in combination with other reported sensitivities along the visual ERP waveform, support a multiple-views-plustransformation account of object cognition positing that the underlying representations code the 2-D images of the object views experienced (Schendan \& Kutas, 2003).

Taken together with the reported view-dependence of N350 modulations, the local feature-independent N350 effects in the present study implicate the global shape of the whole object and/or its parts, but not the local contour features, in the multiple-views format of the representations in the object model selection system. Whereas our prior object memory experiments involved changed viewpoints (Schendan \& Kutas, 2003), in the present work, each object was seen from the same viewpoint across all pictorial variants. Test and study pictures thus shared the same global shapes, such that memory representations for these higher-order structures could be reactivated at test. The ERP data indicated that these global shapes were reactivated and influenced processing during the N350. Consistent with a global shapes hypothesis, frontocentral N350 repetition effects were the same size, despite changes in the local features specifying the global object shapes: N350 effects did not differ between fragmented pictures of objects seen previously in the identical fragment, the same fragment with lines of half the length, and the complementary fragment, as well as intact pictures with continuous or segmented contours. These ERP results are consistent with behavioral findings that object priming is unaffected by changes in the specific lines and vertices present in the image (Cooper, Biederman, \& Hummel, 1992; Biederman \& Cooper, 1991). They are also consonant with neuroimaging evidence that object-sensitive areas in the posterior ventral cortex represent object structure with some visual abstraction, that is, regardless of the specific low-level features composing the shape (Ferber, Humphrey, \& Vilis, 2005; Kourtzi \& Kanwisher, 2001).

Our N350 findings and convergent evidence from cognitive neuroscience motivate us to propose a two-state interactive account of visual object knowledge activation: The posterior ventral, object-sensitive cortex is activated in an initial fast feedforward sweep that supports lower-order image classification abilities, such as face detection (e.g., discriminating faces vs. other objects; Schendan, Ganis, \& Kutas, 1998), and is indexed by an early P150-N170 (i.e., a frontocentral P150 and its polarity reversed posterior N170; Joyce \& Rossion, 2005). In this state, representations of alignment keys (Ullman, 1996), candidate object models, or object parts are activated. Later during the N350, this occipito-temporal cortex is active again, but this time performing the higher-order neural computations, involving recurrent and feedback interactions within these areas and with other areas, such as ventrolateral prefrontal cortex (Brincat \& Connor, 2006; David, Harrison, \& Friston, 2005), that support more sophisticated cognitive abilities with objects (Kosslyn et al., 1994), as well as implicit object memory (Schendan \& Kutas, 2003) and perhaps familiarity (Curran et al., 2002). This state enables activation of the detailed visual knowledge required for the object model selection or model verification processes involved in abilities, such as basic level categorization of an object into a known class (e.g., dog, car, cup) or identification of individual objects like your cat or his bat (Ganis, Schendan, \& Kosslyn, 2007; Lowe, 2000). This second state of interactive activity also supports phenomenological awareness of this knowledge.

After all, although both the P150-N170 and the later N350 have been localized to the posterior ventral cortex (Sehatpour, Molholm, Javitt, \& Foxe, 2006; Rossion, Joyce, Cottrell, \& Tarr, 2003; Allison, Puce, Spencer, \& McCarthy, 1999), this cortex and the N350 show substantial modulations with higher-order categorization and memory functions, whereas the P150-N170 shows little or none. For example, occipito-temporal activity and the N350, but not the P150-N170, differ substantially between objects that are correctly categorized into a known class (e.g., dog, car, or sofa) relative to unidentified objects and between repeated and new items (e.g., Henson et al., 2004; Schendan \& Kutas, 2002, 2003; Avidan et al., 2002; Bar et al., 2001; Grill-Spector, Kushnir, Hendler, \& Malach, 2000; Grill-Spector et al., 1999; James, Humphrey, Gati, Menon, \& Goodale, 1999; Buckner et al., 1998; Schendan et al., 1998). In addition, backward masking, which is thought to disrupt the recurrent neural processes that support phenomenological consciousness (Lamme \& Roelfsema, 2000), impairs categorization performance and attenuates the N350 but not the P150-N170 (Bacon-Mace, Mace, Fabre-Thorpe, \& Thorpe, 2005; Jeffreys, 1996). 
Finally, although the ERP time course might suggest that perceptual grouping, indexed by the occipitotemporal P2 from 200 to $300 \mathrm{msec}$, precedes activation of object representations, indexed by the N350, we propose an intermediate view: Lower-order representations activated in the initial feedforward pass (during the P150-N170) can influence perceptual grouping, whereas higher-order structural representations supporting later model selection processes (during the N350) cannot. Only P200 repetition effects (Schendan \& Kutas, in press) are consistent with the grouping TAP hypothesis (Table 1). Moreover, only the less selective representations reflected in the P150-N170, but not the more precise representations reflected in the N350, are in a temporal position to influence the grouping processes reflected in the $\mathrm{P} 200$. This interpretation is consistent with (1) behavioral findings that some object representations influence perceptual processes, such as figure-ground segregation (Peterson, de Gelder, Rapcsak, Gerhardstein, \& Bachoud-Levi, 2000; Peterson \& Gibson, 1994), (2) fMRI evidence that posterior ventral cortices may be involved in perceptual grouping and figure-ground segregation (Ferber et al., 2005), and (3) magneto-encephalographic findings suggesting top-down modulation within $235 \mathrm{msec}$ from this cortex on grouping processes in lower-level cortex (V1/V2) (Halgren, Mendola, Chong, \& Dale, 2003). The ERP time course suggests that any perceptual grouping contribution from object-sensitive areas precedes their central role in categorization.

\section{Posterior LPC, Secondary Categorization Processes, and Memory}

Whereas the earlier representations, indexed by the P200 (Schendan \& Kutas, in press) and the N350, do not seem to contain information about local features in images, the present findings suggest that later implicit or explicit recollective memory does. The pattern of repetition effects post-500 msec (including posterior N400, P600, and beyond, referred to as LPC) indicates activation of representations that include knowledge about lower-order features of line size, or orientation or location, consistent with the local feature hypothesis. Across both experiments, the LPC is smaller for unstudied than studied objects between 400 and 850 msec. Starting around the $\mathrm{P} 600$ peak, the LPC repetition effect was greater for objects that shared features across study and test than those that did not, that is, larger in the Same and both Intact conditions relative to the Complementary and Half conditions. The LPC is large and broadly distributed across the head, has an extended duration, and multiple intracranial sources reflecting multiple categorization, memory, and response-related processes (Guillem, N'Kaoua, Rougier, \& Claverie, 1995). Like the earlier N350, the LPC varies with categorization success, however, unlike the N350, the LPC shows categorization modulations for any image, regardless of part recoverability, and may index a fronto-parietal network for secondary categorization-related processes, such as selection of an appropriate response, including a name (Schendan \& Kutas, 2002). Although LPC repetition effects could reflect implicit memory for these later categorization processes, most evidence relates these effects to conscious recollection (Duarte et al., 2004; Paller et al., 1995). Our feature-specificity findings would thus be consistent with evidence for greater form-specificity in explicit than implicit memory systems (Schacter \& Buckner, 1998).

\section{Conclusions: Visual Perception, Object Categorization, and Memory}

The ERP results provide direct neurophysiological evidence that the format of object representations varies with the particular neural processing or memory system engaged to accomplish task goals (Figures $4 \mathrm{~A}$ and 5). Three distinct ERP repetition effects-P200, N350, and LPC-delineate the time course of visual object perception, categorization, and memory as follows. Perceptual grouping operations reflected in P200 occur between 200 and $250 \mathrm{msec}$ (Schendan \& Kutas, in press). Within 300 to $400 \mathrm{msec}$, object model selection processes match the organized percept to stored visual knowledge about object structure in PRSs, that is, generic memory and perceptual implicit memory systems, as indicated by the N350. Our two-state interactive hypothesis proposes that these processes take place at a second stage of neural computation in the ventral posterior cortex involving recurrent and feedback interactions and support phenomenological awareness of visual object knowledge. The P200 and N350 findings support a view of implicit memory as a multifaceted system due to the multipartite nature of the human neocortex and characterize the PRSs involved as containing multiple view representations that include visual knowledge about the global shape of the whole object and/or of its intermediate parts, but have visual constancy for line size or orientation, or location. Once an appropriate object model has been found, associated knowledge can be activated, and the appropriate naming response selected, as indexed by LPC effects from 500 to $850 \mathrm{msec}$. Around this time, the human brain may also begin incidentally to recollect having seen the object before, depending upon how well particular local features in the studied and currently perceived images coincide. The different representations and processes reflected in the distinct P200, N350, and LPC repetition effects likely contribute in a cumulative fashion to behavioral RT priming, which was largest in the Same condition (Figures 4C and 5D). In addition, the ERP findings overall provide further evidence for an integrated multiple memory systems and TAP account of human memory: Effects of experience on neural systems 
for implicit and explicit memory are a function of the degree to which initial processing of an event is appropriate for the processing demands of the neural function active at that time in information processing during the memory test (Schendan \& Kutas, 2003). Further, the findings also answer the key timing question of whether implicit memory can be activated before explicit memory. Specifically, transfer of grouping processes or overlap of global shapes is important earlier in processing when perceptual implicit memory is activated during the P200 and N350, respectively, whereas overlap of local contours is important later when processes related to explicit recollection are active during the LPC.

\section{Acknowledgments}

This work was supported by Tufts University faculty research funds to H. E. S., and grants MH52893 and AG05914 to M. K. who was a Lady Davis Fellow during the writing of this manuscript. H. E. S. was responsible for all aspects of design, implementation, data recording and analysis, and manuscript preparation.

Reprint requests should be sent to Haline E. Schendan, Department of Psychology, Tufts University, The Psychology Building, 490 Boston Avenue, Medford, MA 02155, or via e-mail: Haline E.Schendan@tufts.edu; URL: http://ase.tufts.edu/psychology/vmn/.

\section{Notes}

1. The patterns of ERP repetition effects predicted for each hypothesis are not specific to any particular ERP component (or even dependent measure). For example, if one hypothesis explains all repetition effects, then all ERP effects, regardless of their timing, will show the predicted pattern; instead, if different hypotheses explain ERP repetition effects at different times, then ERP effects will differ over time, with the ERP at each distinct time showing the effects pattern that the corresponding hypothesis predicts.

2. Study phase electrophysiology helped ensure subjects would look at the objects in a similar way, and without eye movements or blinks, during both study and test phases. Study phase ERPs were explored but were not informative.

\section{REFERENCES}

Allison, T., Puce, A., Spencer, D. D., \& McCarthy, G. (1999). Electrophysiological studies of human face perception: I. Potentials generated in occipitotemporal cortex by face and non-face stimuli. Cerebral Cortex, 9, 415-430.

Avidan, G., Harel, M., Hendler, T., Ben-Bashat, D., Zohary, E., \& Malach, R. (2002). Contrast sensitivity in human visual areas and its relationship to object recognition. Journal of Neurophysiology, 87, 3102-3116.

Bacon-Mace, N., Mace, M. J., Fabre-Thorpe, M., \& Thorpe, S. J. (2005). The time course of visual processing: Backward masking and natural scene categorisation. Vision Research, 45, 1459-1469.

Bar, M., Tootell, R. B., Schacter, D. L., Greve, D. N., Fischl, B., Mendola, J. D., et al. (2001). Cortical mechanisms specific to explicit visual object recognition. Neuron, 29, 529-535.

Biederman, I. (1987). Recognition-by-components: A theory of human image understanding. Psychological Review, 94, 115-117.

Biederman, I., \& Cooper, E. E. (1991). Priming contour-deleted images: Evidence for intermediate representations in visual object recognition. Cognitive Psychology, 23, 393-419.

Brincat, S. L., \& Connor, C. E. (2006). Dynamic shape synthesis in posterior inferotemporal cortex. Neuron, 49, 17-24.

Buckner, R., Goodman, J., Burock, M., Rotte, M., Koutstaal, W., Schacter, D. L., et al. (1998). Functional-anatomic correlates of object priming in humans revealed by rapid presentation event-related fMRI. Neuron, 20, 285-296.

Bülthoff, H. H., Edelman, S. Y., \& Tarr, M. J. (1995). How are three-dimensional objects represented in the brain? Cerebral Cortex, 5, 247-260.

Cave, C. B., \& Kosslyn, S. M. (1993). The role of parts and spatial relations in object identification. Perception, 22, $229-248$.

Cooper, E. E., Biederman, I., \& Hummel, J. E. (1992). Metric invariance in object recognition: A review and further evidence. Canadian Journal of Psychology, 46, 191-214.

Curran, T., Tanaka, J. W., \& Weiskopf, D. M. (2002). An electrophysiological comparison of visual categorization and recognition memory. Cognitive, Affective, $\&$ Behavioral Neuroscience, 2, 1-18.

David, O., Harrison, L., \& Friston, K. J. (2005). Modelling event-related responses in the brain. Neuroimage, 25, 756-770.

Dobbins, I. G., Schnyer, D. M., Verfaelle, M., \& Schacter, D. L. (2004). Cortical activity reductions during repetition priming can result from rapid response learning. Nature, 428, 316-319.

Duarte, A., Ranganath, C., Winward, L., Hayward, D., \& Knight, R. T. (2004). Dissociable neural correlates for familiarity and recollection during the encoding and retrieval of pictures. Brain Research, Cognitive Brain Research, 18, 255-272.

Ferber, S., Humphrey, G. K., \& Vilis, T. (2005). Segregation and persistence of form in the lateral occipital complex. Neuropsychologia, 43, 41-51.

Gabrieli, J. D., Keane, M. M., Stanger, B. Z., Kjelgaard, M. M., Corkin, S., \& Growdon, J. H. (1994). Dissociations among structural-perceptual, lexical-semantic, and event-fact memory systems in Alzheimer, amnesic, and normal subjects. Cortex, 30, 75-103.

Ganis, G., Schendan, H. E., \& Kosslyn, S. M. (2007). Neuroimaging evidence for object model verification theory: Role of prefrontal control in visual object categorization. Neuroimage, 34, 1384-1398.

Grill-Spector, K., Kushnir, T., Edelman, S., Avidan, G., Itzchak, Y., \& Malach, R. (1999). Differential processing of objects under various viewing conditions in the human lateral occipital complex. Neuron, 24, 187-203.

Grill-Spector, K., Kushnir, T., Hendler, T., \& Malach, R. (2000). The dynamics of object-selective activation correlate with recognition performance in humans. Nature Neuroscience, 3, 837-843.

Guillem, F., N'Kaoua, B., Rougier, A., \& Claverie, B. (1995). Intracranial topography of event-related potentials (N400/ P600) elicited during a continuous recognition memory task. Psychophysiology, 32, 382-392.

Halgren, E., Mendola, J., Chong, C. D., \& Dale, A. M. (2003). Cortical activation to illusory shapes as measured with magnetoencephalography. Neuroimage, 18, 1001-1009.

Henson, R. N., Rylands, A., Ross, E., Vuilleumeir, P., \& Rugg, M. D. (2004). The effect of repetition lag on electrophysiological and haemodynamic correlates of visual object priming. Neuroimage, 21, 1674-1689.

Hintzman, D. L. (1978). The psychology of learning and memory. San Francisco: Freeman.

Hochberg, Y. (1988). A sharper Bonferroni procedure for multiple tests of significance. Biometrika, 75, 800-802.

Holcomb, P. J., \& McPherson, W. B. (1994). Event-related 
brain potentials reflect semantic priming in an object decision task. Brain and Cognition, 24, 259-276.

James, T. W., \& Gauthier, I. (2006). Repetition-induced changes in BOLD response reflect accumulation of neural activity. Human Brain Mapping, 27, 37-46.

James, T. W., Humphrey, G. K., Gati, J. S., Menon, R. S., \& Goodale, M. A. (1999). Repetition priming and the time course of object recognition: An fMRI study. NeuroReport, 10, 1019-1023.

Jeffreys, D. A. (1996). Evoked potential studies of face and object processing. Visual Cognition, 3, 1-38.

Joyce, C., \& Rossion, B. (2005). The face-sensitive N170 and VPP components manifest the same brain processes: The effect of reference electrode site. Clinical Neurophysiology, 116, 2613-2631.

Khoe, W., Freeman, E., Woldorff, M. G., \& Mangun, G. R. (2006). Interactions between attention and perceptual grouping in human visual cortex. Brain Research, 1078, 101-111.

Koffka, K. (1935). Principles of gestalt psychology. New York: Harcourt, Brace and Company.

Kosslyn, S. M., Alpert, N. M., Thompson, W. L., Chabris, C. F., Rauch, S. L., \& Anderson, A. K. (1994). Identifying objects seen from different viewpoints. A PET investigation. Brain, 117, 1055-1071.

Kourtzi, Z., \& Kanwisher, N. (2001). Representation of perceived object shape by the human lateral occipital complex. Science, 293, 1506-1509.

Lamme, V. A., \& Roelfsema, P. R. (2000). The distinct modes of vision offered by feedforward and recurrent processing. Trends in Neurosciences, 23, 571-579.

Leboe, J. P., Whittlesea, B. W., \& Milliken, B. (2005). Selective and nonselective transfer: Positive and negative priming in a multiple-task environment. Journal of Experimental Psychology: Learning, Memory, and Cognition, 31, 1001-1029.

Lowe, D. G. (2000). Towards a computational model for object recognition in IT cortex. Paper presented at the First IEEE International Workshop on Biologically Motivated Computer Vision, Seoul, Korea.

Luck, S. J. (2005). An introduction to the event-related potential technique. Cambridge: MIT Press.

McPherson, W. B., \& Holcomb, P. J. (1999). An electrophysiological investigation of semantic priming with pictures of real objects. Psychophysiology, 36, 53-65.

Morris, C. D., Bransford, J. D., \& Franks, J. J. (1977). Levels of processing versus transfer appropriate processing. Journal of Verbal Learning \& Verbal Behavior, 16, 519-533.

Paller, K. A., Kutas, M., \& McIsaac, H. K. (1995). Monitoring conscious recollection via the electrical activity of the brain. Psychological Science, 6, 107-111.

Palmer, S. E., \& Rock, I. (1994). Rethinking perceptual organization: The role of uniform connectedness. Psychonomic Bulletin \& Review, 1, 29-55.

Peterson, M. A. (1994). The proper placement of uniform connectedness. Psychonomic Bulletin \& Review, 1, 509-514.

Peterson, M. A., de Gelder, B., Rapcsak, S. Z., Gerhardstein, P. C., \& Bachoud-Levi, A. (2000). Object memory effects on figure assignment: Conscious object recognition is not necessary or sufficient. Vision Research, 40, 1549-1567.

Peterson, M. A., \& Gibson, B. S. (1994). Must figure-ground organization precede object recognition? An assumption in peril. Psychological Science, 5, 253-259.

Picton, T. W., Bentin, S., Berg, P., Donchin, E., Hillyard, S. A., Johnson, R., Jr., et al. (2000). Guidelines for using human event-related potentials to study cognition: Recording standards and publication criteria. Psychophysiology, 37, $127-152$.

Rossion, B., Joyce, C. A., Cottrell, G. W., \& Tarr, M. J. (2003). Early lateralization and orientation tuning for face, word, and object processing in the visual cortex. Neuroimage, 20, 1609-1624.

Rugg, M. D., Mark, R. E., Walla, P., Schloerscheidt, A. M., Birch, C. S., \& Allan, K. (1998). Dissociation of the neural correlates of implicit and explicit memory. Nature, 392, 595-598.

Schacter, D. L., \& Buckner, R. L. (1998). On the relations among priming, conscious recollection, and intentional retrieval: Evidence from neuroimaging research. Neurobiology of Learning and Memory, 70, 284-303.

Schacter, D. L., Reiman, E. M., Uecker, A., Polster, M. R., Yun, L. S., \& Cooper, L. A. (1995). Brain regions associated with retrieval of structurally coherent visual information. Nature, 376, 587-590.

Schendan, H. E., Ganis, G., \& Kutas, M. (1998).

Neurophysiological evidence for visual perceptual categorization of words and faces within $150 \mathrm{~ms}$. Psychophysiology, 35, 240-251.

Schendan, H. E., \& Kutas, M. (2002). Neurophysiological evidence for two processing times for visual object identification. Neuropsychologia, 40, 931-945.

Schendan, H. E., \& Kutas, M. (2003). Time course of processes and representations supporting visual object identification and memory. Journal of Cognitive Neuroscience, 15, 111-135.

Schendan, H. E., \& Kutas, M. (in press). Neurophysiological evidence for transfer appropriate processing of memory: Processing transfer versus feature overlap. Psychonomic Bulletin \& Review.

Schendan, H. E., Searl, M. M., Melrose, R. J., \& Stern, C. E. (2003). An fMRI study of the role of the medial temporal lobe in implicit and explicit sequence learning. Neuron, 37, 1013-1025.

Sehatpour, P., Molholm, S., Javitt, D. C., \& Foxe, J. J. (2005). Spatiotemporal dynamics of human object recognition processing: An integrated high-density electrical mapping and functional imaging study of "closure" processes. Neuroimage, 29, 605-618.

Simons, J. S., Koutstaal, W., Prince, S., Wagner, A. D., \& Schacter, D. L. (2003). Neural mechanisms of visual object priming: Evidence for perceptual and semantic distinctions in fusiform cortex. Neuroimage, 19, 613-626.

Snodgrass, J. G., \& Feenan, K. (1990). Priming effects in picture fragment completion: Support for the perceptual closure hypothesis. Journal of Experimental Psychology: General, 119, 276-296.

Snodgrass, J. G., \& Vanderwart, M. (1980). A standardized set of 260 pictures: Norms for name agreement, image agreement, familiarity, and visual complexity. Journal of Experimental Psychology: Human Learning and Memory, 6, 174-215.

Squire, L. R. (1992). Memory and the hippocampus: A synthesis from findings with rats, monkeys, and humans. Psychological Review, 99, 195-231.

Tanaka, K. (2003). Columns for complex visual object features in the inferotemporal cortex: Clustering of cells with similar but slightly different stimulus selectivities. Cerebral Cortex, 13, 90-99.

Tulving, E., \& Schacter, D. L. (1990). Priming and human memory systems. Science, 247, 301-306.

Ullman, S. (1996). High-level vision: Object recognition and visual cognition. Cambridge: MIT Press.

Voss, J. L., \& Paller, K. A. (2006). Fluent conceptual processing and explicit memory for faces are electrophysiologically distinct. Journal of Neuroscience, 26, 926-933.

Wagner, A. D., Maril, A., \& Schacter, D. L. (2000). Interactions between forms of memory: When priming hinders new episodic learning. Journal of Cognitive Neuroscience, 12(Suppl. 2), 52-60.

Wechsler, D. (1981). Wechsler Adult Intelligence ScaleRevised: Manual. New York: The Psychological Corporation. 